\section{Summary and Conclusions}

A trial to assess the best method of preparing suitable material for the routine infusion treatment of coagulation disorders is reported. The following conclusions have been reached:

1. Cryoprecipitate is an extremely valuable therapeutic material for the treatment of haemophilia, particularly where high levels of factor VIII need to be reached and maintained; in young patients; and for patients with incipient congestive cardiac failure. From many points of view it is the therapeutic material of choice.

2. Fresh-frozen plasma in plastic bags is effective provided that the factor VIII level to be attained need not be higher than $20-25 \%$, and provided that the volume to be infused can be tolerated. It has the added advantage that it can be used for the treatment of Christmas disease and other factor deficiencies as well as for haemophilia.

3. "Fresh Frozen Plasma" as supplied to some hospitals in glass bottles is often unsuitable for the treatment of haemophilia. It can be used for the treatment of patients with serum-factor deficiencies.

A change-over on a national scale from glass bottles to the closed plastic-bag system offers a solution to the problem of providing adequate therapeutic material for the treatment of haemophilia. Apart from providing material rich in factor VIII, the method also yields other useful blood components.

We acknowledge with thanks the preliminary work of Dr. Charmian Goldwyn in establishing the bank of fresh-frozen plasma at the North-western Branch of the Royal Free Hospital ; the technical assistance of Miss M. I. Clatworthy; and the help of Dr. Anita M. Follows (Ali). We thank the medical students who have so willingly donated blood; also Baxter's Laboratories Ltd. for a free supply of plastic bags.

This report is based on a paper read at the meeting of the Association of Clinical Pathologists in London in September 1966.

\section{REFERENCES}

Anstall, H. B., Grove-Rasmussen, M., and Shaw, R. S. (1961). Transfusion, 1, 87

Bennett, E., and Dormandy, K. (1966). Lancet, 2, 731.

Biggs, R., and Macfarlane, R. G. (1962). Human Blood Coagulation and its Disorders, 3rd ed., p. 404 . Oxford (1966). Treatment of Haemophilia and Other Coagulation Disorders, p. 350 . Oxford.

Brown, D. L., Hardisty, R. M., Kosoy, M. H., and Bracken, C. (1967). Brit. med. 7., 2, 79 .

Dormandy, K. M., Gandy, R. R., Follows (Ali), A. M., and Britten, M. I. (1967). Communication given to the 10th World Congress of the International Society for the Rehabilitation of the Disabled, WiesInternational society for the Res.

beissly, R. (1925). $7 b$. Kinderheilk., 110, 297.

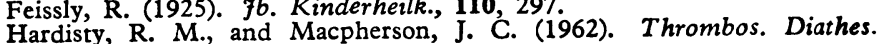
haemorrh. (Stuttg.), 7, 215 .

Kliman, A., and Schwab, P. J. (1961). Amer. J. clin. Path., 36, 379.

Payne, W. W., and Steen, R. E. (1929). Brit. med. F., 1, 1150 .

Pool, J. G., and Shannon, A. E. (1965). New Engl. f. Med., 273, 1443. Preston, A. E. (1967). Brit. F. Haemat., 13, 42.

Simson, L. R., Oberman, H. A., Penner, J. A., Lien, D. M., and Warner, C. L. (1966). Amer. 7. clin. Path., 45, 373.

Walter, C. W. (1950). Surg. Forum, 1, 483

Walter, C. W. Ouart. Rev. Med., p. 129. Button, L. N., and Ritts, R. E. (1957). Surg. Gynec. Obstet., 105, 365. and Murphy, W. P. (1952). Ibid., 94, 687.

\title{
Controlled Trial of Demigran in the Prophylaxis of Migraine
}

\author{
P. HUDGSON,* M.B., M.R.A.C.P. ; J. B. FOSTER, $\dagger$ M.B., M.R.C.P. ; D. J. NEWELL, $\ddagger$ M.A., PH.D.
}

Brit. med. F., 1967, 2, 91-93

Effective preventive treatment of migraine remained a hope rather than a reality for many years until the introduction of the lysergic acid derivative, methysergide, in 1959. Subsequent studies, including a double-blind cross-over trial (Southwell et al., 1964), have shown that it is an effective prophylactic in about $70 \%$ of all cases of recurrent severe migraine. However, attention has also been directed towards the possible application of corticosteroid hormones in the prophylaxis of migraine because of the well-known variations in the severity of the disease with menstruation, pregnancy, and, of late, the use of oral contraceptives (Mears and Grant, 1962; Whitty et al., 1966). Trials have been carried out with androgens (Blumenthal and Fuchs, 1951 ; Jönsson et al., 1951 ; Keil, 1953 ; Moehlig, 1955 ; Roberts, 1955 ; Als and Jacobsen, 1964) and parenteral progesterone (Singh et al., 1947 ; Blumenthal and Fuchs, 1951 ; Steinkamm, 1951 ; Adlercreutz, 1953 ; Keil, 1953 ; Schneider, 1955). However, both methods of treatment have serious disadvantages, androgens because of their virilizing effect and progesterone because of the inconvenience of giving injections over a long period of time. Interest has therefore centred on the development of oral progestational agents, and several of these have been shown to have at least some effect in preventing recurrent attacks of migraine (Lundberg, 1962, 1963).

Lundberg (1965) claimed that a modified oral progestogen, $6 \alpha$-trifluoromethyl-17 $\alpha$-acetoxyprogesterone (W.G.537, Demigran) is particularly effective in this respect. This drug was prepared by Godtfredsen and Vangedal (1961), and was claimed to have no progestational or metabolic effects in the human (Sørensen, 1964), though Lundberg (1965) reported minor dis- turbances of menstrual rhythm in 12 out of 32 women taking the drug in doses between 10 and $20 \mathrm{mg}$. daily. It was therefore decided to subject the drug to a crossover trial, the results of which are reported in this paper. After consideration we decided to use methysergide rather than placebo as the control. This was done for two reasons ; firstly, because of its established efficacy as a prophylactic in migraine, and, secondly, because we felt that it was unreasonable to ask patients with frequent severe attacks to submit to placebo treatment for long periods. This was, we felt, particularly important in those patients in whom partial or complete prophylaxis had already been effected by some form of interval treatment. In this context it should be noted that, in spite of the obvious disadvantage of using tablets of different appearances, the code was not broken by any of the patients who completed the trial.

\section{Patients}

Fifty-three patients were included in the trial. All had frequent severe attacks of typical migraine, and had required interval treatment at some time in the past. Most of them were under 40 , but a few of middle age were included who had frequent disabling attacks. The average number of headaches

\footnotetext{
* Senior Registrar in Neurology.

† Consultant Neurologist.

₹ Reader in Biostatistics.

Regional Neurological Centre, Newcastle General Hospital, and the
Nuffield Department of Industrial Health, University of Newcastle upon Tyne.
} 
suffered monthly by these patients before interval treatment varied from 2 to 30 . Three patients were excluded from the trial who were otherwise suitable, but who had previously shown unfavourable reactions to methysergide.

\section{Treatment}

Half of the patients received Demigran $5 \mathrm{mg}$. ( 1 tablet) three times daily (the dose recommended by the manufacturer) for four months, then had one month without specific treatment, and then had methysergide $1 \mathrm{mg}$. (1 tablet) three times daily for four months. The other half of the patients received the treatments in reverse order.

Allocation of Patients to Treatment Groups.-The patients were allocated to the "Demigran first" or " methysergide first" group according to a list prepared from a table of random numbers. In fact, this allocated 27 to start on methysergide and 26 on Demigran. In the course of the nine-month period 18 patients were withdrawn from the trial. Of these, seven on methysergide and five on Demigran failed to attend for followup during the first half of the trial (including one patient who was killed as a passenger in a motor-car accident and another who became pregnant). Three further patients developed more frequent and more severe migraine attacks, and one developed recurrent syncopal attacks (with a normal E.E.G.), all while on Demigran. The final patient withdrawn had completed treatment with Demigran, then developed side-effects while on methysergide in the second half of the trial.

Criterion of Success of Treatment.-Each patient in the trial was issued with a diary card on which to record day by day the occurrence of attacks. Patients were seen every month, when the card was checked, and inquiry was made to ensure that all recorded headaches were in fact migrainous. For each patient the average number of headaches monthly on each treatment was used as the basis of analysis, with the corresponding number before interval treatment also available in their records. At the monthly sessions the examining physicians did not know which treatment the patient was taking at the time.

\section{Analysis of Results}

This analysis is based on the 35 patients who completed treatment with both drugs. Before interval treatment the most common number of attacks was four a month, but these varied between 2 and 30 headaches a month. The distribution was far from Gaussian, and no simple transformation would normalize it. Accordingly, a simple distribution-free analysis was required.

Seven patients had the same number of attacks with Demigran as with methysergide. Of the 28 patients who showed any difference between the two drugs, 23 had more headaches with Demigran. This result is highly significant. Had the two drugs been equivalent we would expect a 50:50 split; the probability of the observed result is less than 0.005 .

The magnitude of the improvement is more difficult to express, in view of the irregular distribution of attacks in these patients. Of the 23 who had fewer attacks with methysergide 17 had only half, or less than half, the number with Demigran. Two patients who had daily attacks throughout the trial both reported that the attacks were less severe in the methysergide period than the Demigran; if they are excluded the average number of monthly attacks while on Demigran was 4.3 and on methysergide was 2.8 .

Comparison of the trial results with those obtained before the treatment started is a rather doubtful procedure. The fact of being involved in a trial may change the patient's recorded headaches. With this proviso, further analysis shows that of 24 patients who had different results on Demigran from the pretreatment records 15 had few attacks on Demigran and nine had more. This result is not significantly different from $50: 50$ $(P=0.3)$.

Only three patients had more attacks with methysergide than without any interval treatment.

Side-effects.-None of the male patients taking Demigran complained of any untoward side-effects. Of the 21 female patients 15 were in the reproductive age range. Of these, five developed polymenorrhoea on Demigran, each of them menstruating at intervals of from one to two weeks. This symptom cleared rapidly in each case after the drug was withdrawn. One patient developed nausea, vomiting, and vertigo while on methysergide, and this became so severe that withdrawal from the trial was necessary. No other side-effects were observed.

\section{Discussion}

The chronic incapacity of those patients with recurrent severe attacks of migraine and the difficulties experienced in their management are well known. Until the introduction of methysergide there was little or no prospect that such patients could be assured of effective interval treatment for any length of time. Even with the use of this drug Southwell et al. (1964) found that attacks persist unabated in some $30 \%$ of cases. Because of this and because migraine is influenced by hormonal factors the recent suggestions that it may be ameliorated or even abolished by oral progestogens has obvious significance. Accordingly we felt that it would be well worth while subjecting this new progesterone derivative, shown to be apparently free from endocrine activity in both laboratory and clinical studies (Hasselmann and Roholt, 1964; Sørensen, 1964), to the scrutiny of a cross-over trial.

The decision to use methysergide as the control was taken principally on the ethical grounds previously noted. In addition, due consideration was given to the risk of inducing undesirable side-effects with this drug, particularly retroperitoneal fibrosis (Graham, 1964 ; Utz et al., 1965 ; Graham et al., 1966). However, it was decided that the evidence adduced on this point was not sufficiently clear-cut to occasion real concern. The other known side-effects of methysergide-namely, vertigo, unsteadiness, nausea, and vomiting-are unpleasant, but all disappear rapidly after withdrawal of the drug. That the use of tablets of differing appearances did not invalidate the status of the trial is evidenced by the fact that the code remained unbroken throughout in all patients who completed the trial. The only side-effect produced by Demigran in our experience was polymenorrhoea, which was of greater severity than that reported by Lundberg (1965), who found in women who developed menstrual disturbances while taking Demigran that the duration of the cycle was reduced by a few days only.

The superiority of methysergide to Demigran shown by this trial was very marked. Two points which demand comment, however, are as follows:

1. The trial was restricted to patients who had not, in previous experience, reacted unfavourably to methysergide. It might appear that the trial would have been fairer if it had been restricted to patients who had never been exposed to methysergide at all. In the event, however, four patients deteriorated on Demigran, and were unable to complete the trial. The exclusion of these patients counteracts the effect of excluding the three patients who produced side-effects with methysergide. We cannot say how any of these excluded patients would have responded to the other drug.

2. The exclusion of unequal numbers from the two groups meant that in the analysable results 20 patients started on methysergide but only 15 on Demigran. In various changeover trials of this type an advantage to the first drug given has been reported, and this might have introduced a bias against Demigran. In this particular trial, however, there was no marked advantage for the first drug. The drug given first 
(whether methysergide or Demigran) was preferred by 16 patients, and that given second was preferred by 12 , a nonsignificant difference.

ADDENDUM.- Since the completion of this trial we have been advised by the manufacturers of Demigran that its formulation has been altered to give more satisfactory absorption characteristics when administered by mouth. We have been assured that this modification has been achieved without affecting its pharmacological properties in any way. Further, we have been told that in Europe, where the drug is in more general clinical use, higher doses than those originally recommended are now being given. We have therefore decided to embark on a further trial of this drug with the modified preparation and the new dosage schedules. The results of that study will be reported in due course.

The Demigran tablets used in this trial were supplied by Leo Laboratories Limited. We wish to thank Dr. John N. Walton for permission to study those patients included who had been under his care. We are also grateful to Miss Y. Riches for secretarial assistance.

\section{REFERENCES}

Adlercreutz, E. (1953), Acta med scand., 145, 15

Als, E., and Jacobsen, J. J. (1964). Ugeskr. Lag., 126, 1355

Blumenthal, L. S., and Fuchs, M. (1951). Amer. Practit., 2, 755.

Godufredsen, W. O., and Vangedal, S. (1961). Acta chem. scand., 15, 1786

Graham, J. R. (1964). New Engl. 7. Med., 270, 67.

Suby, H. I., LeCompte, P. R., and Sadowsky, N. L. (1966). Ib!d., $274,359$.

Hasselmann, G., and Roholt, K. (1964). Unpublished observations. Jönsson, B., von Reis, G., and Sahlgren, E. (1951). Acta psychiat. scand.

Keil, Ch. (1953). Rev. méd. Liège, 8, 521

Lundberg, P. O. (1962). Acta endocr. (Kbh.), 40, Suppl. No. 68, p. 5.

Lundberg, P. O. (1962). Acta endocr. (Kbh.), (1963). Svenska Läk.-Tidn., 60, 2789.

Mears, E., and Grant, E. C. G. (1962). Brit. med. 7., 2, 75.

Moehlig, R. C. (1955). f. Mich. med. Soc., 54, 577.

Roberts, S. E. (1955). Arch. Otolaryng., 61, 401.

Schneider, J. A. (1955). Med. Welt., 1, 212.

Singh, I., Singh, I., and Singh, D. (1947). Lancet, 1, 745.

Sørensen, B. (1964). Unpublished observations.

Southwell, N., Williams, J. D., and Mackenzie, I. (1964). Lancet, 1, 523.

Steinkamm, E. (1951). Med. Klin., 46, 211.

Utz, D. C., Rooke, E. D., Spittell, J. A., and Bartholomew, L. G. (1965) Utz, D. C., Rooke, E. D., Spittell,

Whitty, C. W. M., Hockaday, J. M., and Whitty, M. M. (1966). Lancet, 1,856 .

\section{Medical Memoranda}

\section{Delayed Traumatic Rupture of Colon with Colocutaneous Fistula}

\section{Brit. med. F., 1967, 2, 93-94}

Rupture of the colon is one of the less common consequences of non-penetrating abdominal trauma, accounting for about $3 \%$ of the injuries found at laparotomy (Lawson, 1952; Clarke, 1954 ; Christensen et al., 1955 ; Helsper, 1955 ; Fitzgerald et al., 1960 ; Watkins, 1960 ; Currie et al., 1964 ; Simpson, 1966). Though the usual colonic injury is an intraperitoneal perforation, gangrene of the bowel may result from vascular damage (Mathieson, 1962).

Delayed intraperitoneal rupture of the large bowel has previously been reported (Brit. med. F., 1953). Though retroperitoneal rupture of the colon (Myers, 1959) and caecum (Gordon-Taylor, 1952) with abscess formation have been recorded, spontaneous formation of a colocutaneous fistula after closed abdominal injury does not seem to have been described.

Two cases are presented in which colocutaneous fistula developed six weeks and 19 days after non-penetrating abdominal injuries.

\section{CASE 1}

A 17-year-old youth was injured in a car accident. He sustained a fracture of the left clavicle, a fracture of the right seventh rib, and a fracture-dislocation of the fourth lumbar vertebra without neurological damage. A right pneumothorax was treated with an intercostal drain. Intra-abdominal injuries were suspected and laparotomy disclosed a tear in the caecal wall, the mucosa remaining intact. No other intra-abdominal lesion was noted. Nine days after his injury the right lung had re-expanded and intercostal drainage was discontinued. Two weeks after injury the patient was immobilized on a plaster bed.

Six weeks after injury an abscess pointed above the left iliac crest and discharged spontaneously. The cavity was explored under general anaesthesia and an oblique track communicating with the descending colon was found. The defect in the posterior wall of the colon admitted two fingers. A direct pathway for drainage was established.

After operation the faecal discharge was collected in Chiron disposal ileostomy bags for about four weeks, dry dressings then being adequate. Three months after injury the patient was discharged home wearing a polyethylene jacket over his dressings. Drainage from the fistula stopped four months after injury; he was then fit and well.

A barium enema one year after injury showed that the descending colon was adherent to the lateral abdominal wall at the site of the

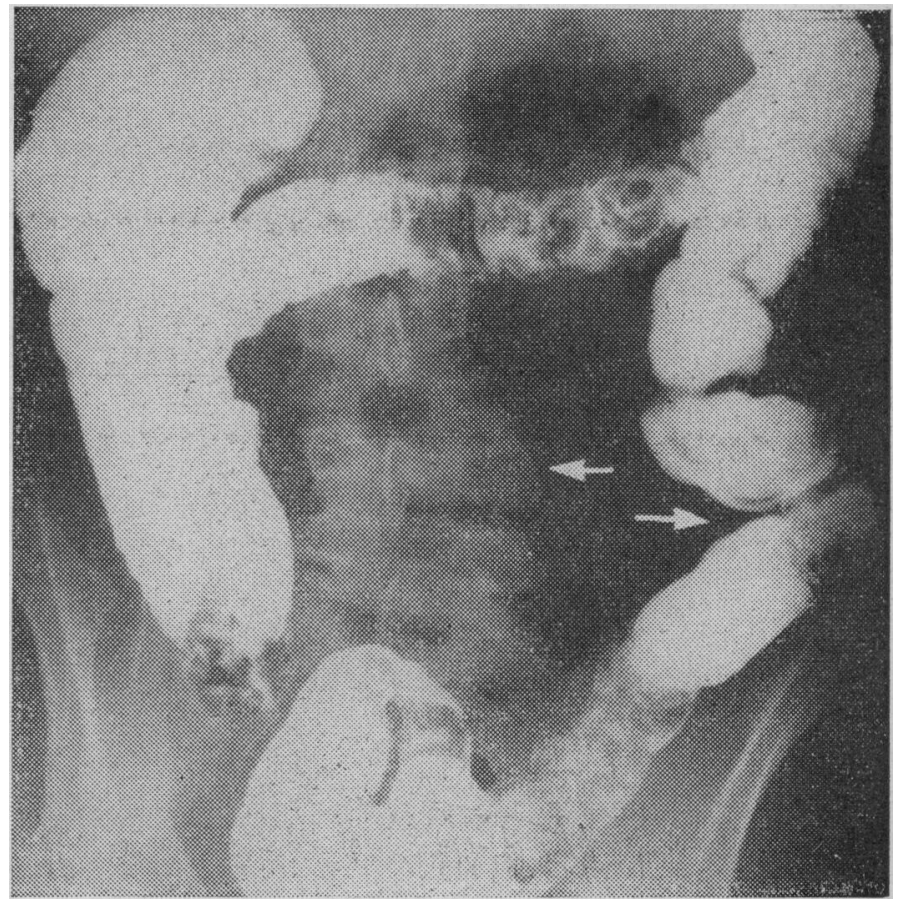

Case 1. Barium enema one ycar after injury. The fracture-dislocation of the fourth lumbar veriebra is seen. The descending colon is adherent to the abdominal wall at the site of the fistula above the left iliac crest There is no evidence of stricture formation. 